\title{
Dynamics of ignition of stoichiometric hydrogen-air mixtures by moving heated particles
}

\author{
J. Melguizo-Gavilanes*, S. Coronel, R. Mével, J.E. Shepherd \\ Graduate Aerospace Laboratories, California Institute of Technology (GALCIT), Pasadena, CA, \\ USA
}

\begin{abstract}
Studying thermal ignition mechanisms is a key step for evaluating many ignition hazards. In the present work, two-dimensional simulations with detailed chemistry are used to study the reaction pathways of the transient flow and ignition of a stoichiometric hydrogen/air mixture by moving hot spheres. For temperatures above the ignition threshold, ignition takes place after a short time between the front stagnation point and separation location depending upon the sphere's surface temperature. Closer to the threshold, the volume of gas adjacent to the separation region ignites homogeneously after a longer time. These results demonstrate the importance of boundary layer development and flow separation in the ignition process.
\end{abstract}

Key words: hot particle ignition, industrial safety, aircraft safety, numerical simulation, hydrogen

${ }^{*}$ Corresponding author: josuemg@caltech.edu 


\section{Introduction}

Assessing the risk of accidental ignition of flammable mixtures is an issue of importance in industry and aviation[1]. Typical thermal ignition sources include concentrated hot surfaces, moving hot particles and extended hot surfaces [2]. In aircraft, potential ignition sources include lightning strikes, sparks from electrical equipment, electrostatic discharge in fuel tanks, and overheated pumps $[3,4,5]$. One such ignition hazard is introduced through the use of carbon fiber reinforced polymers (CFRP) as an alternative to aluminum alloys in aircraft manufacturing, i.e. the Boeing 787 Dreamliner features over $50 \%$ CFRP by structural weight. The use of CFRP in aircraft introduces problems in the event of a lightning strike due the structure's poor electrical conductivity when compared to aluminum structures. Carbon is a good electrical conductor, however, the addition of the polymer matrix increases the overall electrical resistance of the CFRP. In the case of a lightning strike on a composite aircraft structure, hot particles can be ejected from the surface that is struck due to resistive heating. Resistive heating of the material leads to pyrolisis of the resin and fiber which can further lead to an explosive release of the heated material due to gases developing from the burning resins [6]. The ejected heated material, i.e. the hot particles, represent a potential ignition hazard if they are ejected into flammable vapor regions such as the ullage inside the fuel tank.

Previous experiments on hot particle ignition include a particle heated in a furnace and then injected into an explosive atmosphere, as well as a stationary particle placed in an explosive atmosphere and heated via laser light. The former experiment was performed by Silver [7] using two different particle materials, quartz and platinum. Varying the particle material had minimal effect on the minimum ignition temperature of three different flammable mixtures: a 10\% coal-gas-air mixture, $3 \%$ pentane-air mixture, and a $20 \%$ hydrogen-air mixture. For a fixed gas mixture, the results suggest that the size and temperature of a particle are important factors in determining whether ignition occurs. The data indicate that as particle size increases, the minimum temperature required for ignition decreases. The experiments performed by Silver were done with particle speeds varying from $2-5 \mathrm{~m} / \mathrm{s}$; however, the effect of particle speed was not investigated systematically. Beyer and 
Markus [8] performed studies using inert particles suspended in an explosive atmosphere and heated via laser light. The combustible mixtures used were pentane-air, propane-air, ethylene-air and hydrogen-air. The studies showed that the particle ignition temperature was weakly dependent on the mixture composition but was highly dependent on which combustible gas was used. The particle ignition temperature was also highly dependent on the particle diameter. More recently, Roth et al. [9] studied the ignition of hydrogen-air mixtures by submillimeter sized particles and determined that the particle material (silicon nitride, tungsten carbide, steel, casting steel, and aluminum) had an effect on the ignition temperature for a fixed mixture composition. Their study suggests that chemically inert particles show the lowest surface temperature required for ignition when compared to the metal particles. Additional work on stationary hot particle ignition via laser light has been performed in $[10,11,12,14,13,15]$. A comparison of the experimental data of Beyer and Markus [8], and Silver [7], for a pentane-air mixture suggests that, for a given diameter of the particle, a moving particle will have a higher ignition temperature than a stationary particle. Paterson [16] measured a $300 \mathrm{~K}$ increase in ignition temperature for a $2 \mathrm{~mm}$ diameter sphere injected into a $9 \%$ coal-gas-air mixture at 10 $\mathrm{m} / \mathrm{s}$ and later at $65 \mathrm{~m} / \mathrm{s}$. In addition, Paterson [17] performed experiments, similar to Silver [7], in coal-gas-air, pentane-air, and hydrogen-air, at lower particle speeds of $1.2 \mathrm{~m} / \mathrm{s}$. Paterson [17] found a lower surface temperature, by $100 \mathrm{~K}$, needed for ignition of a $3 \%$ pentane-air mixture when compared to Silver's results. Previous numerical and theoretical studies have been limited to 1-D simulations of stationary particles assuming spherical symmetry $[8,9]$, and to stagnation point ignition of premixed combustible mixtures using boundary layer equations, one-step irreversible reactions and asymptotic approximations [18, 19, 20, 21].

The present study focuses on the ignition of reactive mixtures by moving heated spheres through two-dimensional numerical simulations. In order to avoid the computational costs associated with the integration of the large chemical mechanisms typical of hydrocarbon fuels, we chose to investigate the ignition event using a stoichiometric hydrogen-air mixture. Hydrogen is one of the fuels for which the chemistry is reliably known, and the detailed mechanism is of reasonable size to simulate 
realistic geometries. Additionally, it represents a promising alternative fuel, hence, understanding the risks associated with its use justify continued research efforts. The aim of this study is not to quantify ignition thresholds as a function of mixture composition or fuel, analyze effect of particle size or material like in the previous experimental and numerical work cited above, but to explain the dynamics of the ignition process close to the minimum temperature required to induce ignition as well as at much higher temperatures. We examine the competition between diffusive and convective losses, and chemical heat release within the thermal boundary layer to unravel the key physical and chemical processes at play during ignition.

\section{Physical model and computational methodology}

\subsection{Governing equations}

We model the motion, transport and chemical reaction in the gas surrounding the particle by the variable-density reactive Navier-Stokes equations with temperature dependent transport properties.

$$
\begin{gathered}
\partial_{t}(\rho)+\nabla \cdot(\rho \mathbf{u})=0 \\
\partial_{t}(\rho \mathbf{u})+\nabla \cdot(\rho \mathbf{u u})=-\nabla p+\nabla \cdot \tau+\rho \mathbf{g} \\
\partial_{t}\left(\rho Y_{i}\right)+\nabla \cdot\left(\rho \mathbf{u} Y_{i}\right)=-\nabla \cdot \mathbf{j}_{\mathbf{i}}+\dot{\omega}_{i} \\
\partial_{t}\left(\rho h_{s}\right)+\nabla \cdot\left(\rho \mathbf{u} h_{s}\right)=-\nabla \cdot \mathbf{j}_{\mathbf{q}}+\dot{q}_{\text {chem }} \\
p=\rho \bar{R} T, \quad \tau=\mu\left[\nabla \mathbf{u}+(\nabla \mathbf{u})^{T}\right]-\frac{2}{3} \mu(\nabla \cdot \mathbf{u}) \mathbf{I}
\end{gathered}
$$

In Eqs. (1)-(5), $\rho, p$ and $T$ are the gas density, pressure and temperature, $\mathbf{u}$ is the velocity vector, $h_{s}$ is the mixture sensible enthalpy, $\mathbf{g}$ is the gravitational acceleration, $Y_{i}$ is the mass fraction of species, $\mathbf{j}_{\mathbf{i}}$ is the species diffusion flux, $\dot{\omega}_{i}$ represents the rate of production/consumption of species, $\mathbf{j}_{\mathbf{q}}$ is the heat flux, $\dot{q}_{\text {chem }}=-\sum_{i=1}^{N} \Delta h_{f, i}^{o} \dot{\omega}_{i}$ is the rate of conversion of chemical into thermal energy, $\Delta h_{f, i}^{o}$ is the enthalpy of formation of species, $\bar{R}$ is the specific gas constant, $\tau$ is the deviatoric stress tensor, $\mu$ is the mixture viscosity, and $\mathbf{I}$ is the identity matrix. Radiation is neglected in the current numerical model. The species diffusion term, $\mathbf{j}_{\mathbf{i}}$, uses Fick's law for binary mixtures. For multicomponent mixtures where one component is present in large 
amounts (i.e. $\mathrm{N}_{2}$ for combustion in air) all other species may be treated as trace species. Writing the binary diffusion coefficient with respect to $\mathrm{N}_{2}$ only yields:

$$
\mathbf{j}_{\mathbf{i}}=-\rho D_{i} \nabla Y_{i}, \text { with } D_{i}=D_{j, \mathrm{~N}_{2}}
$$

where $D_{i}$ is the effective diffusion coefficient. In Eq. 6, thermodiffusion or Soret effect has been neglected.

We solve the mass conservation equation, Eq. 1, and only for $N-1$ species equations. The last species mass fraction, $\mathrm{N}_{2}$, is obtained by writing $Y_{\mathrm{N}_{2}}=1-$ $\sum_{i=1}^{N-1} Y_{i}$ and absorbs all inconsistencies introduced by Fick's law. This error is negligible when the last species, $Y_{\mathrm{N}_{2}}$, is at a high concentration as is the case for combustion in air [22].

The heat flux $\mathbf{j}_{\mathbf{q}}$ includes the effect of sensible enthalpy transport by diffusion

$$
\mathbf{j}_{\mathbf{q}}=-\frac{\kappa}{c_{p}} \nabla h_{s}+\sum_{i=1}^{N-1} h_{s, i}\left(\mathbf{j}_{\mathbf{i}}+\frac{\kappa}{c_{p}} \nabla Y_{i}\right)
$$

where $\kappa$ and $c_{p}$ are the mixture averaged thermal conductivity and specific heat, respectively. In Eq. 7, the Dufour effect (i.e. energy flux due to a concentration gradient) has not been taken into account [23]. Substituting Eq. 6 into 7 yields:

$$
\mathbf{j}_{\mathbf{q}}=-\frac{\kappa}{c_{p}} \nabla h_{s}+\sum_{i=1}^{N-1} h_{s, i}\left(1-\frac{1}{\mathrm{Le}_{i}}\right) \frac{\kappa}{c_{p}} \nabla Y_{i}
$$

where $\operatorname{Le}_{i}=\kappa /\left(c_{p} \rho D_{i}\right)$ is the Lewis number of species $i$. The Lewis number is assumed to be unity for all species which results in $\kappa / c_{p}=\rho D_{i}$. Hence, the dynamic thermal diffusivity of species is used to model its mass diffusivity. The second term on the right hand side of Eq. 8 vanishes if the Lewis numbers of all species are assumed to be unity, simplifying the energy equation significantly. Differential diffusion effects for the present situation have been examined by the authors in [24], and show a modest effect on predicted ignition thresholds.

The equations above are integrated in two dimensions using the Open source Field Operation And Manipulation (OpenFOAM) toolbox [25]. The spatial discretization of the solution domain is performed using finite volumes. Specifically, the convective terms were discretized using a second order, bounded TVD scheme; the mass fractions were discretized using a linear centered scheme for scalars bounded 
between zero and one. The diffusion terms were discretized using the linear centered scheme together with a second order, conservative scheme for the evaluation of the surface normal gradients. The linear systems that result from the discretization of the governing equations are solved through iterative techniques [26]. The PBiCG (Preconditioned Biconjugate Gradient) method is used for all linear systems including the chemical source terms preconditioned through the DILU (Diagonal Incomplete-LU) technique, whereas the Poisson equation for pressure is solved using the PCG (Preconditioned Conjugate Gradient) preconditioned by the DIC (Diagonal Incomplete Cholesky). The pressure-velocity coupling is achieved using the PIMPLE (PISO+SIMPLE) algorithm [27]. Finally, the time-step is dynamically adapted during the course of the computation based on a specified Courant number to ensure stability of the numerical scheme [28]. In the current study the Courant number used is 0.2 .

\subsection{Chemical and transport models}

The chemistry is modeled using Mével's [29, 30] detailed mechanism for hydrogen oxidation which includes 9 species and 21 reactions. The Sutherland Law [31], modified Eucken relation [32] and JANAF polynomials [33] are used to account for the functional temperature dependence of mixture viscosity $(\mu)$, thermal conductivity $(\kappa)$ and specific heat $\left(c_{p}\right)$, respectively.

\subsection{Domain, initial and boundary conditions}

The computational domain consists of a vertical rectangle with a 2D-axisymmetric sphere located at $(0,0,0)$ with diameter $d=4 \mathrm{~mm}$. The top, bottom and side boundaries are placed $15 d, 5 d$ and $10 d$ away from the center of the sphere respectively. A resolution of approximately 300,000 cells is used, with finer resolution near the sphere and a minimum cell size of $60 \mu \mathrm{m}$ to ensure that the thermal/hydrodynamic boundary layers are properly resolved. Figure 1 shows a schematic of the simulation setup. The numerical integration is divided in two parts to reproduce as closely as possible the experimental conditions used by Coronel et al. [34]. First, a free fall in $\mathrm{N}_{2}$ for $0.25 \mathrm{~s}$ (fall time measured experimentally) during which 
a steady thermal boundary layer develops. Second, contact with reactive stoichiometric hydrogen-air mixture $\left(Y_{\mathrm{H}_{2}}=0.0283, Y_{\mathrm{O}_{2}}=0.2264, Y_{\mathrm{N}_{2}}=0.7453\right)$ for $20 \mathrm{~ms}$ (experimental observation window) or until ignition is observed and initial stages of flame propagation take place. Initial conditions are $p_{o}=101 \mathrm{kPa}, T_{o}=300 \mathrm{~K}$, $\mathbf{u}_{o}=(0,0,0) \mathrm{m} / \mathrm{s}$. The surface of the sphere is assumed to be at a fixed (uniform) temperature, $\mathrm{T}_{\text {sphere, }}$ providing an isothermal boundary condition for the gas. Two cases are studied in detail, $960 \mathrm{~K}$ and $1200 \mathrm{~K}$. There is no net flux of species to the wall, and the effects of surface heterogeneous reactions have been ignored. The frame of reference is attached to the sphere, and as a result, a time dependent inflow boundary condition is prescribed at the bottom of the computational domain to properly simulate the fall of the heated particle, as its velocity increases at a rate of $g=9.81 \mathrm{~m} / \mathrm{s}^{2}$, given by $\mathbf{u}(t)=(0, g t, 0) \mathrm{m} / \mathrm{s}$. At the top, a non-reflective/pressure transmissive boundary condition is used to simulate an outflow.
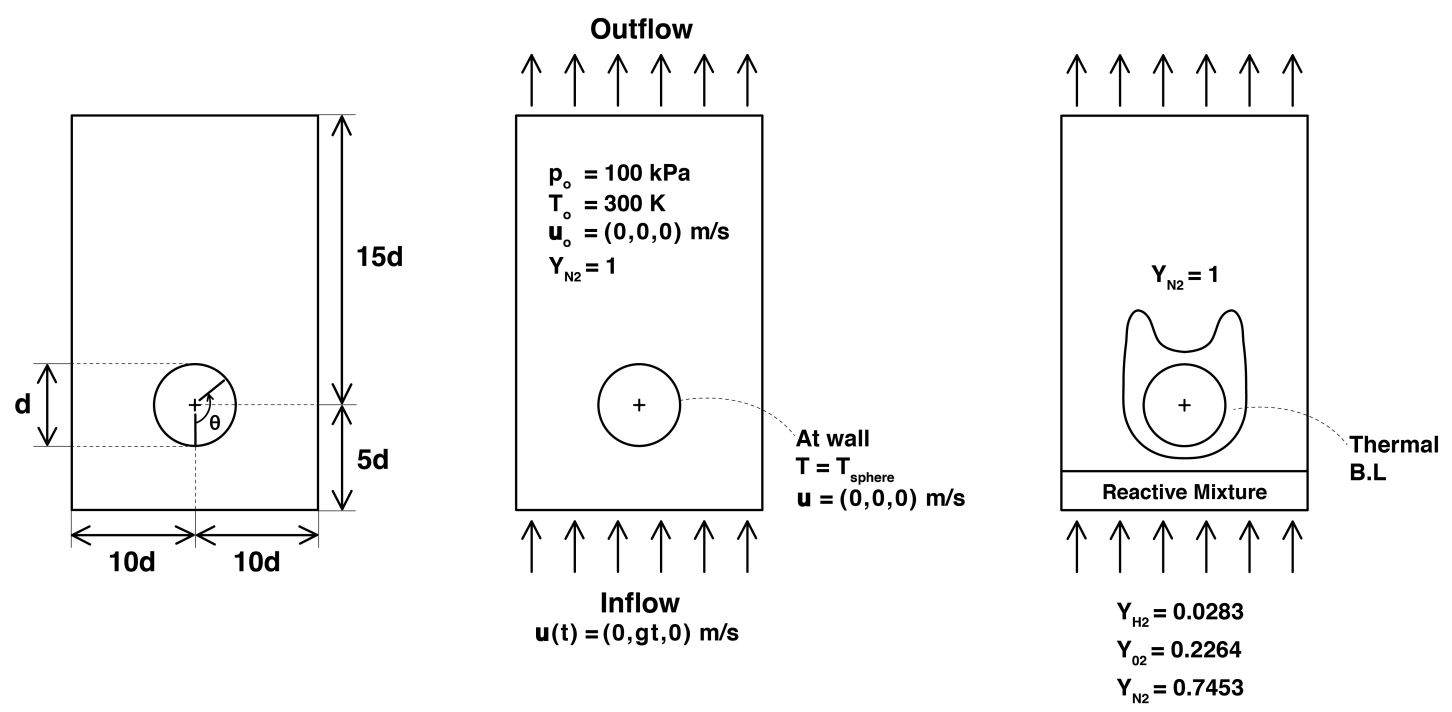

Figure 1: Schematic of simulation setup. Left: computational domain. Center: free fall in $\mathrm{N}_{2}-$ initial and boundary conditions. Right: contact with stoichiometric hydrogen-air mixture.

\section{Results and discussion}

A detailed analysis of the flow field during the ignition event has been performed to identify important features in the flow such as thermal and hydrodynamic bound- 
ary layers, flow separation, velocity distributions and chemical activity.

\subsection{Flow structure}

Figure 2 (left) shows temperature and velocity (magnitude) fields obtained after $t=0.25 \mathrm{~s}$ for $\mathrm{T}_{\text {sphere }}=960 \mathrm{~K}$, together with temperature isocontours taken every $50 \mathrm{~K}$ from 400-950 K, and streamlines to reveal the structure of the flow. A schematic displaying these features is presented in Fig. 2 (right). Specific locations along the sphere are uniquely determined by the angle, $\theta$, measured from the vertical centerline starting at the front stagnation point $\left(\theta=0^{\circ}\right)$ and increasing towards the rear stagnation point $\left(\theta=180^{\circ}\right)$ - see Fig. 1 (left). Development and growth of the thermal boundary layer from the front stagnation point to the region of flow separation in the vicinity of the sphere surface can be observed. There is a small temperature gradient between $110^{\circ} \leq \theta \leq 130^{\circ}$ with temperatures as high as $900 \mathrm{~K}$ half a millimeter away from the sphere surface; this is in contrast with the sharp decrease from $960 \mathrm{~K}$ to $400 \mathrm{~K}$, over the same length scale, at the front stagnation point. The edge of the hot wake of the heated particle is arbitrarily delineated by the $400 \mathrm{~K}$ temperature contour. The velocity (magnitude) field and streamlines show the flow structure around the sphere. The gas is slowed as it approaches the heated particle at the front stagnation point, subsequently it is accelerated as it travels around the sphere, and finally separates near $\theta=115^{\circ}$. The rear stagnation point, and recirculation zone are visible, the length of the recirculation region is $10 \mathrm{~mm}$.

Note that this particular flow is not characterized by a unique Reynolds number, $\operatorname{Re}=U_{\infty} d / \nu$, where $U_{\infty}$ is the free stream flow velocity, $d$ is the sphere diameter, and $\nu$ the kinematic viscosity of the mixture. This is due to the strong dependence of $\nu$ on temperature, increasing by one order of magnitude between $300-1500 \mathrm{~K}$. This results in a variation in Re from $\sim 600$, when considering the viscosity value corresponding to the free stream temperature, to $\sim 80$ and $\sim 50$ when evaluating the gas properties at $950 \mathrm{~K}$ and $1200 \mathrm{~K}$. Figure 3 shows Re and $\nu$ as a function of temperature for $\mathrm{N}_{2}$ and a $\mathrm{H}_{2}$-air stoichiometric mixture for the temperature range of interest. 

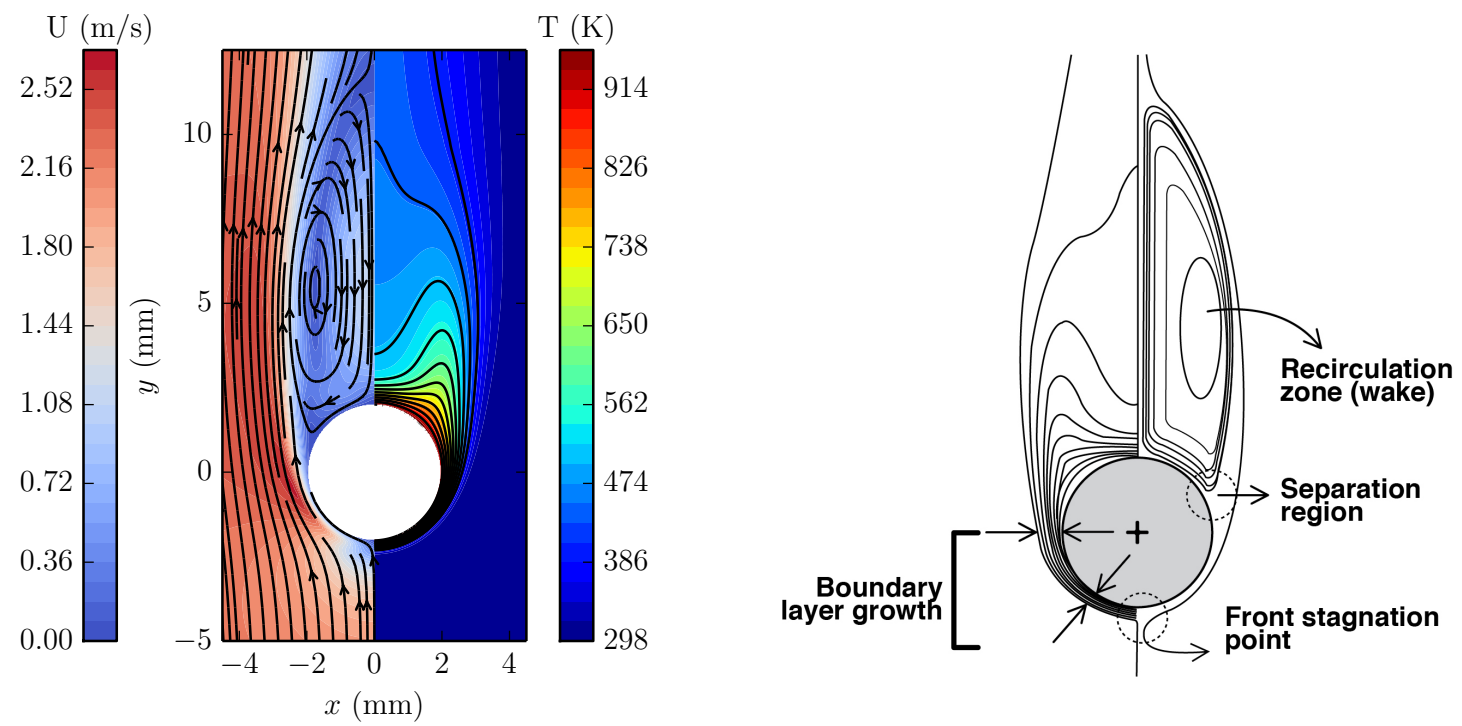

Figure 2: Left: temperature and velocity (magnitude) field in the vicinity of the sphere, temperature isocontours and streamlines. Right: flow structure schematic describing important features present in the flow field.
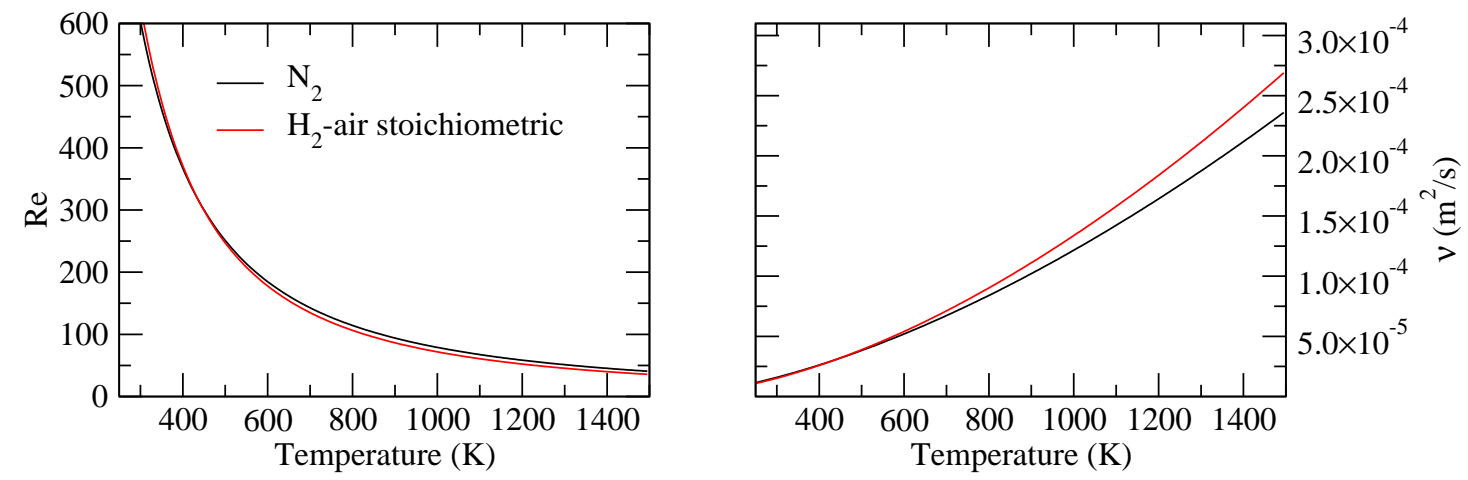

Figure 3: Reynolds number $(\mathrm{Re})$ and kinematic viscosity $(\nu)$ variation as a function of temperature for $\mathrm{N}_{2}$ and stoichiometric $\mathrm{H}_{2}$-air.

\subsection{Time to ignition}

In order to determine the ignition time, $\tau_{\text {ign }}$, in the $2-\mathrm{D}$ simulations, the temperature maximum in the computational domain is monitored during the simulation. For the present study, ignition is defined as the time at which the maximum temperature in the domain reaches $\mathrm{T}_{\text {sphere }}+150 \mathrm{~K}$. The rapid change in temperature during the ignition transient makes the ignition time insensitive to choice of threshold temper- 
ature. Figure 4 shows in detail the evolution of the maximum temperature for three representative sphere surface temperatures. The time to ignition from the initial release of the sphere is $\tau_{\text {ign }}=0.266306 \mathrm{~s}$ and $0.2525 \mathrm{~s}$ for $\mathrm{T}_{\text {sphere }}=960 \mathrm{~K}$ and $1200 \mathrm{~K}$, respectively. Alternatively, measuring time from contact with the reactive mixture, the ignition times are $16.306 \mathrm{~ms}$ and $2.5 \mathrm{~ms}$. At $950 \mathrm{~K}$ the gas does not ignite during the $20 \mathrm{~ms}$ duration of the simulation.

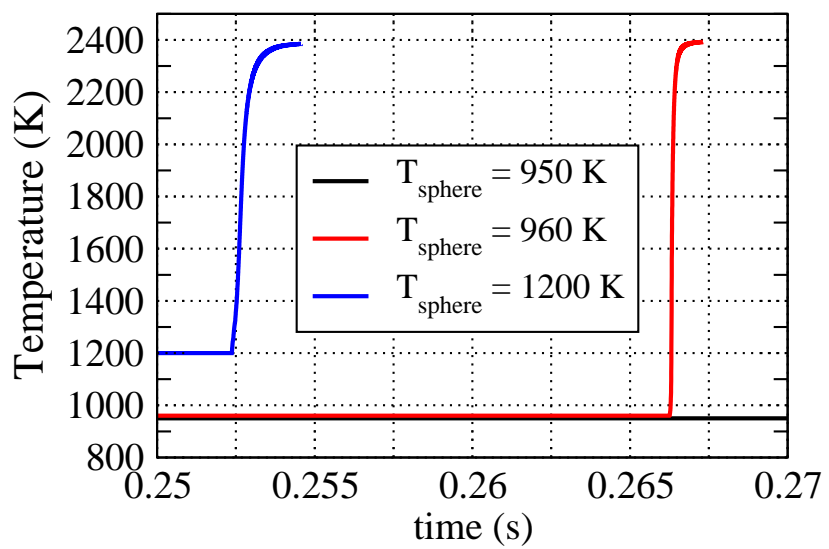

Figure 4: Temperature maximum in computational domain for $\mathrm{T}_{\text {sphere }}=950,960$ and $1200 \mathrm{~K}$.

In Fig. 5, the ignition times obtained from the 2-D simulations for different surface temperatures (red line) are plotted together with adiabatic constant pressure (CP) delay times computed with Mével's mechanism (black line). The ignition time from the 2-D simulation increases rapidly as the temperature of the sphere is decreased to $950 \mathrm{~K}$. This vertical asymptote (black dotted line) indicates the possible existence of a threshold temperature below which ignition does not occur. Further examination of the curve also reveals the existence of a horizontal asymptote (black dashed line) for the temperature above which ignition takes place very rapidly after contact of the sphere with reactive mixture. Above $1100 \mathrm{~K}$, the reaction rates are sufficiently fast that ignition is controlled by heat/species transport rather than chemical kinetics.

The blue solid line (secondary vertical axis) shows the location along the sphere where ignition occurs, $\theta_{\text {ign }}$, for the different surface temperatures considered. The ignition location moves from the front stagnation point $\left(\theta=0^{\circ}\right)$ towards the zone of 
flow separation (near $\theta=115^{\circ}$ ) as the temperature decreases towards the minimum ignition temperature. For all the cases considered, ignition was never observed to occur in the recirculation region, hot wake, or rear stagnation point. In contrast to the 2-D simulation ignition times, the $\mathrm{CP}$ ignition times continue to decrease as the initial temperature of the gas increases. The ratio of 2-D to 0-D ignition times for $960 \mathrm{~K}, 1000 \mathrm{~K}, 1050 \mathrm{~K}, 1100 \mathrm{~K}$ and $1200 \mathrm{~K}$ are 33, 25, 26.4, 38 and 63 respectively. The large differences observed between the two types of simulations are due to the absence of convective and diffusive losses in the constant pressure calculations, and most importantly, due to the fact that it takes some time for reactive $\mathrm{H}_{2}$-air mixture to reach the hot sphere because the boundary layer is initially filled with nitrogen.

To asses the influence of flushing $\mathrm{N}_{2}$ from the boundary layer on the ignition delay times and ignition location, additional simulations were run. The first part of the simulation described in section 2.3 remains unchanged. For the second part however, the entire computational domain was filled with stoichiometric $\mathrm{H}_{2}$-air mixture, thereby, neglecting the sphere interaction with the $\mathrm{N}_{2}$-reactive mixture interface, and the flushing process present in the experiments. The orange line in Fig. 5 shows the ignition delay times obtained without $\mathrm{N}_{2}$ in the boundary layer. Not surprisingly, the ignition results are now closer to those computed using the 0-D CP approximation, with the difference between the traces decreasing with increasing sphere surface temperature. The largest differences occur at lower temperatures (longer simulation times) because diffusive and chemical time scales are roughly of the same order closer to the ignition threshold. As a result, diffusion of radicals away from the ignition location and heat losses to the sphere surface become important. Notably, the ignition threshold remains unchanged. Regarding ignition location, the gas ignites out of the separated region for all cases considered. The increased importance of diffusive processes as the ignition threshold is approached indicate that simplified models based on simple ignition time estimates may not be appropriate to accurately predict ignition thresholds. 


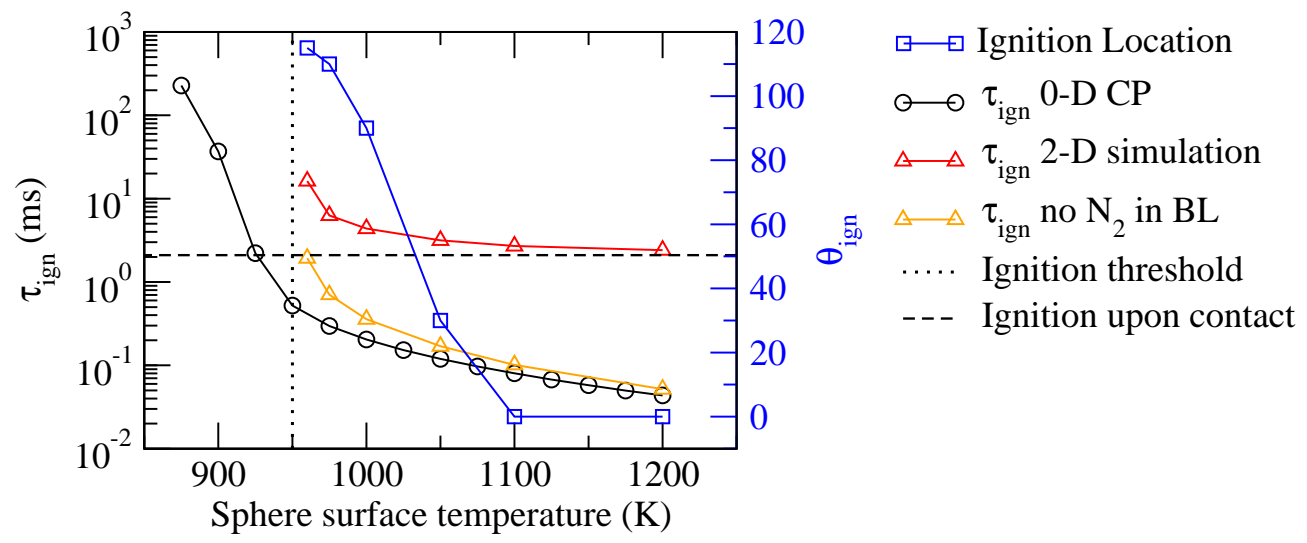

Figure 5: Ignition location and comparison of ignition delay times obtained from 2-D simulations and adiabatic constant pressure (CP) ignition times from Mével mechanism as a function of sphere surface temperature.

\subsection{Ignition process $-T_{\text {sphere }}=1200 \mathrm{~K}$}

The two-dimensional variable fields in Fig. 6 and 7 provide additional insight into the ignition process. The left and right columns of the figure show temperature and velocity (magnitude), and $\mathrm{N}_{2}$ and product $\left(\mathrm{H}_{2} \mathrm{O}\right)$ mass fraction fields at four different instances during the simulation: $130 \mu$ s before ignition; during the ignition event; $250 \mu \mathrm{s}$ after ignition/flame kernel formation; and during early stages of flame propagation. The $\mathrm{N}_{2}$ mass fraction field evolution illustrates the interaction of the sphere with the inert/combustible mixture interface. The solutions at $t=\tau_{\text {ign }}-130 \mu$ s show the thermal and hydrodynamic boundary layer changes (see Fig. 6 left column) as the sphere penetrates the interface (see Fig. 6 right column). The reactive mixture slowly displaces the pure $\mathrm{N}_{2}$ originally present in the thermal boundary layer. On the time scale considered here, this diffusive process results in a $\mathrm{N}_{2}$ concentration within the boundary layer that is higher than that of stoichiometric $\mathrm{H}_{2}$-air. Consequently, a diluted $\mathrm{H}_{2}$-air- $\mathrm{N}_{2}$ mixture undergoes ignition. In the right column of the figure, the section of sphere in contact with reactive mixture, the inert/combustible mixture diffusion layer, and significant chemical activity $\left(\mathrm{H}_{2} \mathrm{O}=\right.$ $0.03)$ taking place upon contact at $\theta=0^{\circ}$ can be observed. During the ignition event, $t=\tau_{\text {ign }}=0.2525 \mathrm{~s}$, the temperature increases from 1200 to $1350 \mathrm{~K}$ and the mass fraction of products from 0.03 to 0.1 . Ignition occurs within the thermal boundary 
layer at the front stagnation point $\left(\theta=0^{\circ}\right), 2.5 \mathrm{~ms}$ after contact with the $\mathrm{H}_{2}$-air mixture. Shortly after ignition, at $t=\tau_{\mathrm{ign}}+250 \mu \mathrm{s}$, a small flame kernel forms and propagates away, ahead of the falling sphere, consuming fresh mixture (see fields at $\left.t=\tau_{\text {ign }}+500 \mu \mathrm{s}\right)$.

\subsection{Ignition process $-T_{\text {sphere }}=960 \mathrm{~K}$}

Figure 7 shows the same variable fields as Fig. 6 but for a sphere surface temperature of $960 \mathrm{~K}$. The temperature and product mass fraction $\left(\mathrm{H}_{2} \mathrm{O}\right)$ fields at $t=\tau_{\text {ign }}-56 \mu$ s confirm that chemical activity is localized in the region where flow separation occurs. This suggests that the reaction rates at this surface temperature are not fast enough to release sufficient heat and trigger fuel conversion into products during fluid element transit from the front stagnation point to the separation region. The gas flow around the sphere results in a separation region near $115^{\circ}$ where reactive mixture is essentially "trapped", conduction of heat from the sphere to the gas takes place readily, and convective losses are minimal (see velocity fields at $\left.t=\tau_{\text {ign }}-56 \mu \mathrm{s}\right)$. The gas in the separation region ignites, and a small flame kernel forms, as seen in the fields at $t=\tau_{\text {ign }}=0.266306 \mathrm{~s}$ and $t=\tau_{\text {ign }}+56 \mu \mathrm{s}$, respectively. At later times, $t=\tau_{\text {ign }}+194 \mu \mathrm{s}$, the nascent flame continues to propagate away from the separation region along the circumference of the sphere, where the mixture is hottest, preferentially towards the front stagnation point and to the sides. At the rear stagnation point and in the recirculation zone there is no combustible mixture to be consumed, only the $\mathrm{N}_{2}$ that is trapped in the wake (see Fig. 7 bottom row). In this case, due to the significantly longer induction time, all the $\mathrm{N}_{2}$ originally present in the boundary layer has already been displaced by $\mathrm{H}_{2}$-Air. The mixture that undergoes ignition is not diluted and has a higher energy content than that of the $1200 \mathrm{~K}$ case.

A number of differences between $T_{\text {sphere }}=1200 \mathrm{~K}$ and $960 \mathrm{~K}$ can be emphasized regarding the early stages of flame propagation shown in the bottom row of Figs. 6 and 7. First, the shape of the flame is mainly determined by the extent of $\mathrm{N}_{2}$ present in the wake. In the $1200 \mathrm{~K}$ case, the flame appears wider and has a rather shallow V-shape at the back, this is because the flame grows and propagates only 

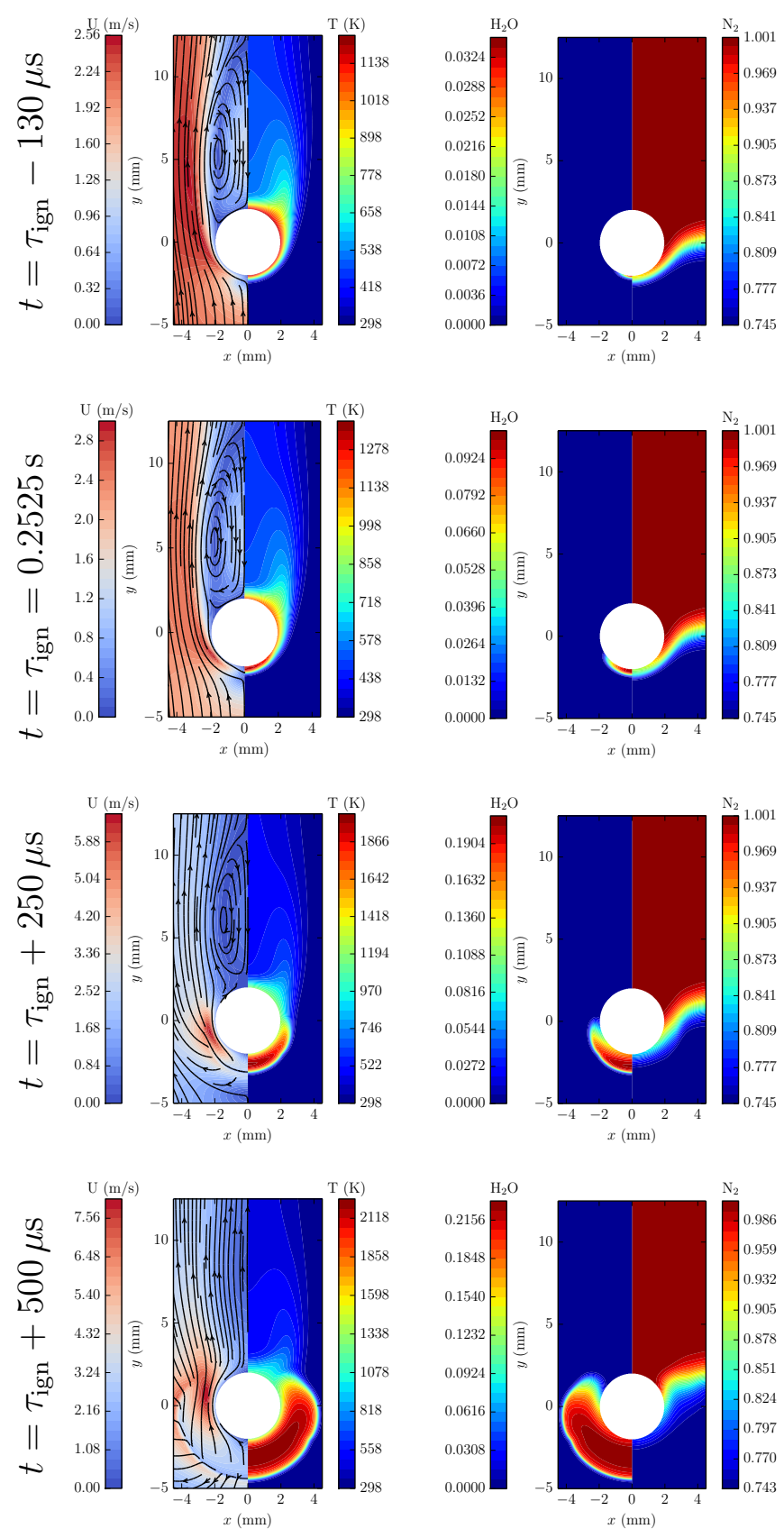

Figure 6: Ignition process for $\mathrm{T}_{\text {sphere }}=1200 \mathrm{~K}$ : temperature and velocity (magnitude) (left), $\mathrm{N}_{2}$ and $\mathrm{H}_{2} \mathrm{O}$ (right) fields at $t=\tau_{\text {ign }}-130 \mu \mathrm{s}$ - before ignition, $t=\tau_{\text {ign }}=0.2525 \mathrm{~s}$ - ignition event, $t=\tau_{\text {ign }}+250 \mu \mathrm{s}$ - ignition/flame kernel formation, and $t=\tau_{\text {ign }}+500 \mu \mathrm{s}$ - early stages of flame propagation.

where combustible mixture is present. In this particular case, ignition occurs after $2.5 \mathrm{~ms}$. The distance the sphere has traveled from the interface into $\mathrm{H}_{2}$-air is very small in this time interval, which results in the "flatter" flame shown. On the 

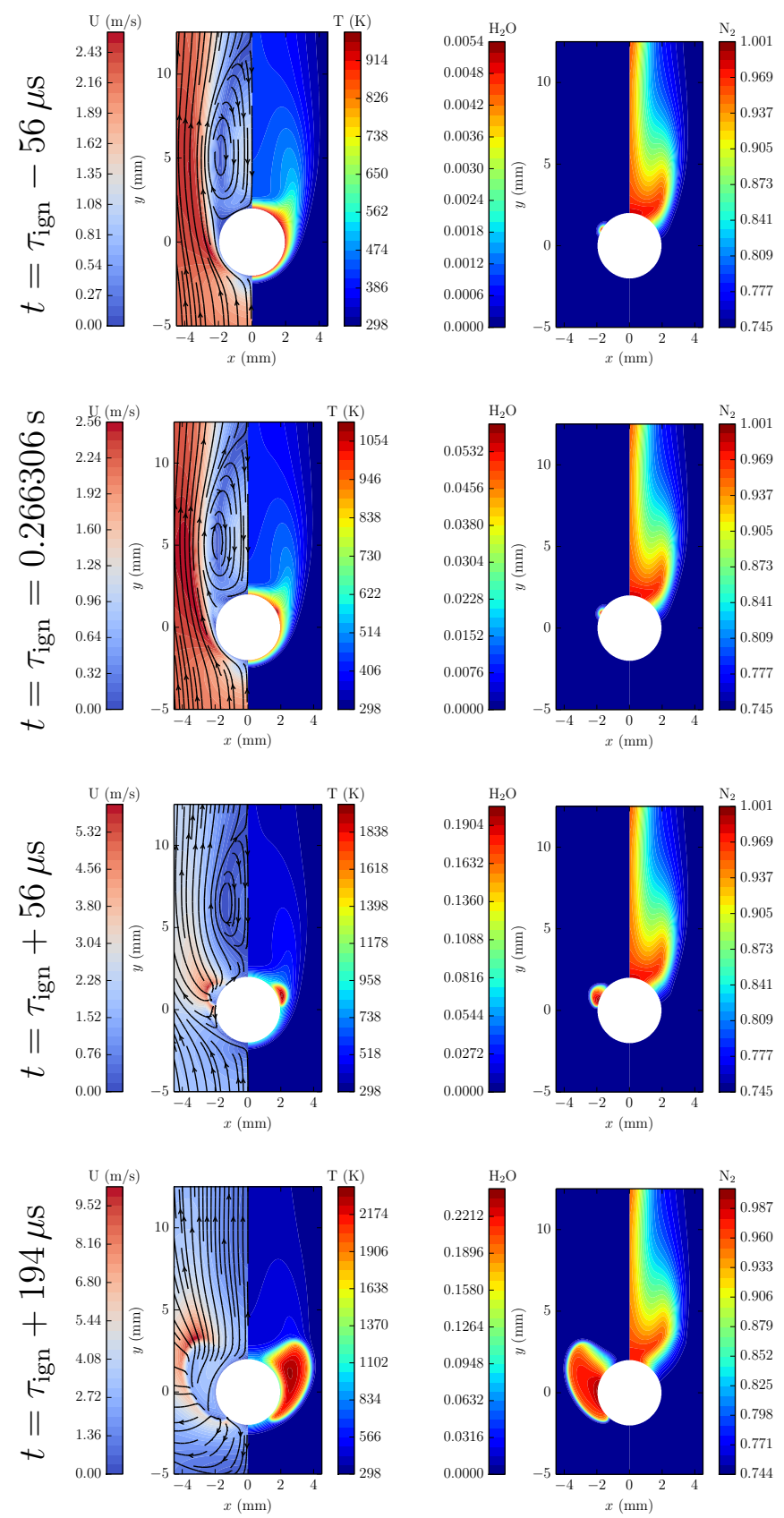

Figure 7: Ignition process for $\mathrm{T}_{\text {sphere }}=960 \mathrm{~K}$ : temperature and velocity (magnitude) (left), $\mathrm{N}_{2}$ and $\mathrm{H}_{2} \mathrm{O}$ (right) fields at $t=\tau_{\text {ign }}-56 \mu \mathrm{s}$ - before ignition, $t=\tau_{\text {ign }}=0.266306 \mathrm{~s}$ - ignition event, $t=\tau_{\text {ign }}+56 \mu \mathrm{s}$ after ignition/flame kernel formation, and $t=\tau_{\text {ign }}+194 \mu \mathrm{s}$ - early stages of flame propagation.

other hand, for the $960 \mathrm{~K}$ case, the sphere travels almost six times as long into the combustible mixture, leaving the interface considerably further away, resulting in a narrower wake and a more pronounced $\mathrm{V}$-shape at the back of the sphere. 
Second, for $\mathrm{T}_{\text {sphere }}=1200 \mathrm{~K}$, the flame runs away from the front stagnation point because the burning speed in stoichiometric $\mathrm{H}_{2}$-air is higher than the speed of the falling sphere. In the $960 \mathrm{~K}$ case however, the flame ignites from the region of flow separation propagating rapidly through the thermal boundary layer toward the front of the sphere. Third, the higher temperature peak for $\mathrm{T}_{\text {sphere }}=960 \mathrm{~K}$, i.e. $2319 \mathrm{~K}$ as opposed to $2246 \mathrm{~K}$ for $\mathrm{T}_{\text {sphere }}=1200 \mathrm{~K}$, is a direct consequence of ignition occurring in an undiluted $\mathrm{H}_{2}$-air mixture in the thermal boundary layer as discussed above.

\subsection{Energy equation analysis}

To unravel the key physical and chemical processes taking place at the ignition location, $\theta=0^{\circ}$ for $\mathrm{T}_{\text {sphere }}=1200 \mathrm{~K}$, and $\theta=115^{\circ}$ for $\mathrm{T}_{\text {sphere }}=960 \mathrm{~K}$, each of the terms in the energy conservation equation is plotted as function of radial distance from the surface of the sphere (see Figs. 8 and 9). The plots are given at the same times as the field images in Figs. 6 and 7 to enable a direct comparison. The abscissas represent the normal radial distance from the surface of the heated sphere, whereas the ordinates show the corresponding energy density and temperature. The solid lines are the convective and diffusive heat losses, and the chemical source term given respectively by $\mathrm{h}_{\text {Convection }}=-\nabla \cdot\left(\rho \mathbf{u} h_{s}\right), \mathrm{h}_{\text {Diffusion }}=\nabla \cdot\left(\kappa / c_{p} \nabla h_{s}\right)$, and $\mathrm{h}_{\text {Source }}=\dot{q}_{\text {chem }}$. The dashed line is their sum, $\mathrm{h}_{\text {Unsteady }}$, and the dashed-dotted line is the temperature.

The earliest temperature trace shows the initial thermal boundary layer thickness, $\delta$, at both ignition locations. At later times temperature trace shows the development of the ignition kernel, the flame and propagation through the thermal boundary layer into the surrounding cold gas. At $\theta=0^{\circ}\left(\mathrm{T}_{\text {sphere }}=1200 \mathrm{~K}\right)$, $\delta_{1200 K}=0.5 \mathrm{~mm}$, and at $\theta=115^{\circ}\left(\mathrm{T}_{\text {sphere }}=960 \mathrm{~K}\right), \delta_{960 \mathrm{~K}}=2 \mathrm{~mm}$. This is consistent with the typical development and growth of a boundary layer on a non-reactive hot sphere.

Shortly before ignition (Figs. 8 and 9 top left), close to the sphere surface, the source term is mostly balanced by diffusion. The dip in the convective term is due to the expansion of the gas taking place in this area as a result of the initial chemical heat release; the sum is positive up to $0.5 \mathrm{~mm}$ normal from the sphere surface, and 

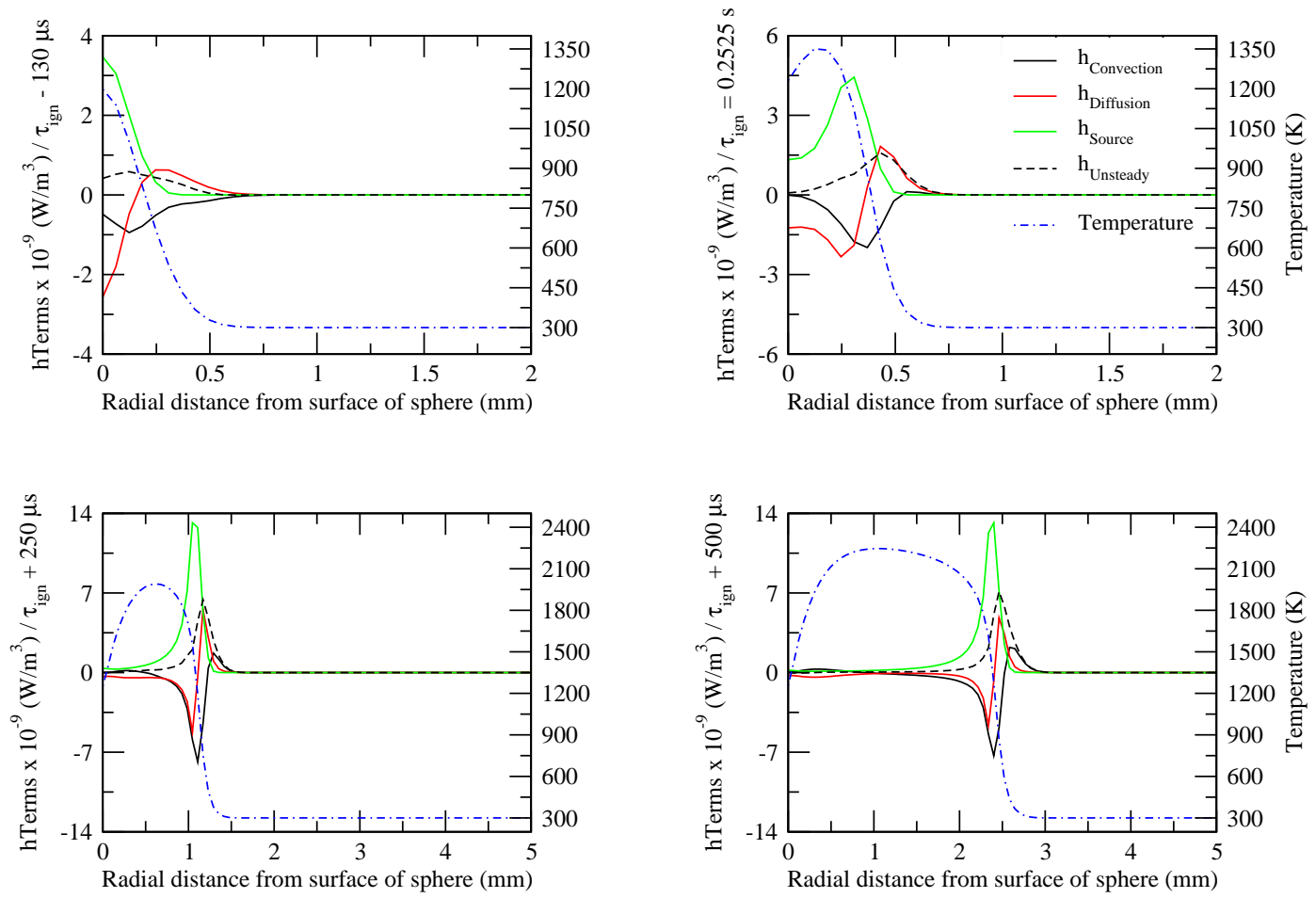

Figure 8: Ignition process for $\mathrm{T}_{\text {sphere }}=1200 \mathrm{~K}$ : contributions of each term in energy equation and temperature along radial distance from surface of sphere at $\theta=0^{\circ}$. Top Left: at $t=\tau_{\mathrm{ign}}-130 \mu \mathrm{s}$ - before ignition. Top Right: $t=\tau_{\text {ign }}=0.2525 \mathrm{~s}$ - ignition event. Bottom Left: at $t=\tau_{\text {ign }}+250 \mu \mathrm{s}$ - ignition/flame kernel formation. Bottom right: at $t=\tau_{\text {ign }}+500 \mu$ s - early stages of flame propagation.

the temperature maximum remains at the wall. Further away from the sphere's wall $(0.5-1 \mathrm{~mm})$, convection balances diffusion (see Fig 8 top left). In Figs. 8 and 9 top right, $130 \mu \mathrm{s}$ and $56 \mu$ s later, the temperature maximum is no longer at the wall but roughly $0.18 \mathrm{~mm}$ and $0.08 \mathrm{~mm}$ away from the surface of the sphere. The rate at which heat is diffused back to the wall is not large enough to balance the heat released by the chemical reactions at these locations. The increase of over 17 times in the source term over $56 \mu \mathrm{s}$ for $\mathrm{T}_{\text {sphere }}=960 \mathrm{~K}$ compared with the 1.5 fold increase over a longer time interval, $130 \mu \mathrm{s}$ for $\mathrm{T}_{\text {sphere }}=1200 \mathrm{~K}$, further supports the idea that when close to the ignition threshold, the volume of gas confined in the separated region ignites homogeneously.

The bottom left plots of Figs. 8 and 9 show the structure of an incipient flame kernel forming, with the chemical source term being balanced mostly by diffusion at 

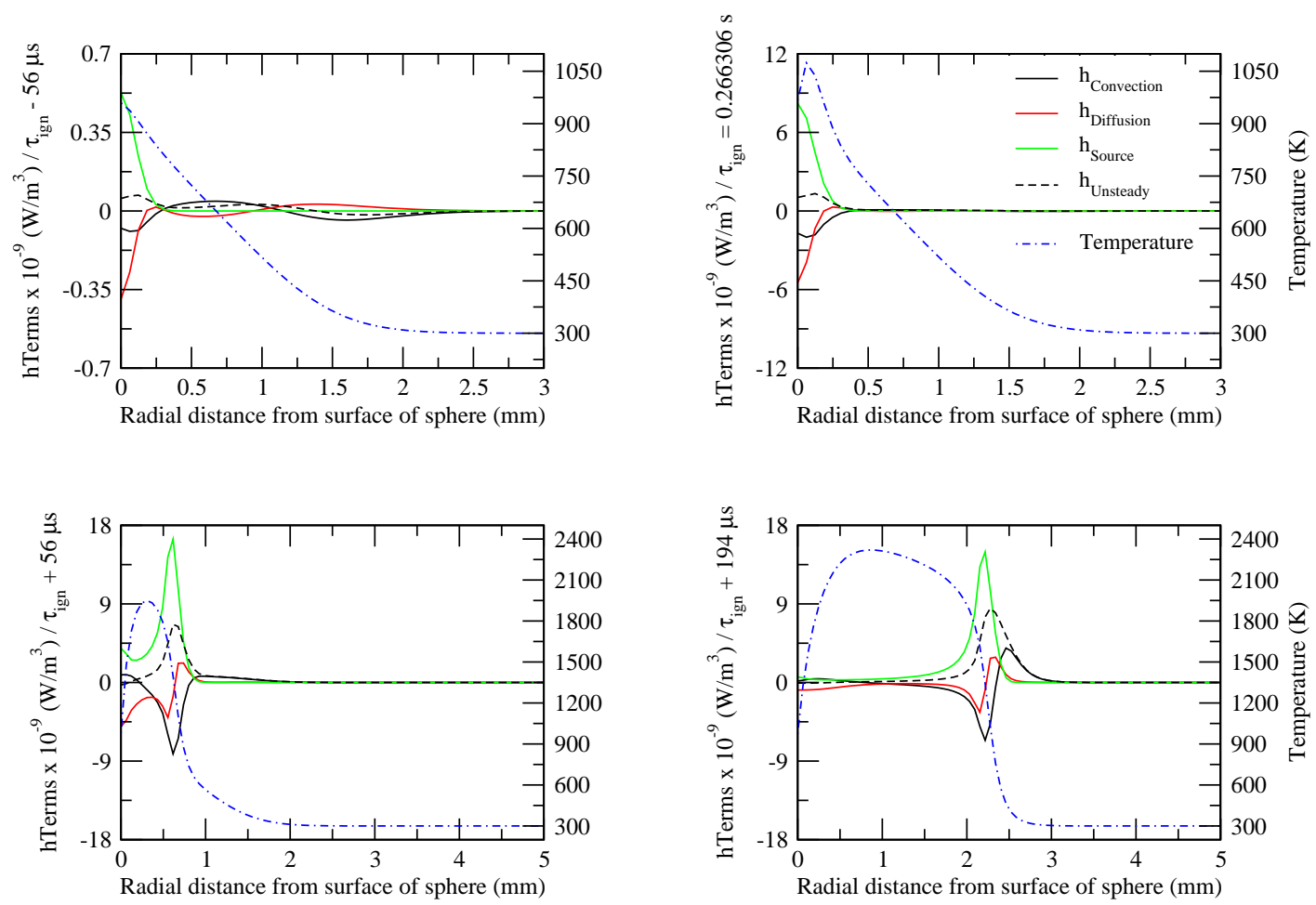

Figure 9: Ignition process for $\mathrm{T}_{\text {sphere }}=960 \mathrm{~K}$ : contributions of each term in energy equation and temperature along radial distance from surface of sphere at $\theta=115^{\circ}$. Top Left: at $t=\tau_{\mathrm{ign}}-56 \mu \mathrm{s}$ before ignition. Top Right: at $t=\tau_{\text {ign }}=0.266306 \mathrm{~s}$ - ignition event. Bottom Left: at $t=\tau_{\text {ign }}+56 \mu \mathrm{s}$ after ignition/flame kernel formation. Bottom right: at $t=\tau_{\text {ign }}+194 \mu$ s - early stages of flame propagation.

the wall, and the structure of a laminar flame emerging $1 \mathrm{~mm}$ and $0.6 \mathrm{~mm}$ from the surface of the sphere, for $1200 \mathrm{~K}$ and $960 \mathrm{~K}$, respectively. The lower peak in the heat release for $\mathrm{T}_{\text {sphere }}=1200 \mathrm{~K}$, namely $13 \times 10^{9} \mathrm{~W} / \mathrm{m}^{3}$, is, as previously mentioned, due to a diluted mixture within the thermal boundary layer when the sphere surface temperature is far away from the ignition threshold, and ignition times are shorter.

The plots at the bottom right of Figs. 8 and 9 very clearly show the flame structure. The flame thickness can be estimated from the figures, it is roughly $0.4 \mathrm{~mm}$ for both cases. As the flame propagates and consumes the reactive mixture, it displaces the gas ahead of it which results in the convection term rapidly increasing to an absolute maximum. The subsequent drop in the convection term represents the expansion of the gas behind the front. Within the flame, the source term peaks abruptly at the inflection point of the temperature trace signaling the ignition of 
fresh mixture, and is counteracted by the combined effect of diffusion and convection.

\subsection{Chemical Pathways}

Species profiles are studied in detail and a reaction pathway analysis is performed to explain the difference in the ignition process at the two temperatures studied. These analyses have been carried out at the ignition location obtained from the 2-D simulations. Figures 10 and 11 show the profiles of each term in the energy equation, temperature and species mass fraction for a sphere temperature of $1200 \mathrm{~K}$ and $960 \mathrm{~K}$, respectively. In both cases, as the chemical source term overcomes the convection and diffusion terms, a sharp increase in temperature is observed along with fast consumption of the reactants and rapid production of the combustion product, $\mathrm{H}_{2} \mathrm{O}$, and of the reactive transient species, $\mathrm{H}, \mathrm{O}$ and $\mathrm{OH}$. This behavior is consistent with previous studies on laminar flame structure or homogeneous ignition, and is typical of the combined thermal and branched-chain explosion for $\mathrm{H}_{2}$-air combustion $[35,36]$.
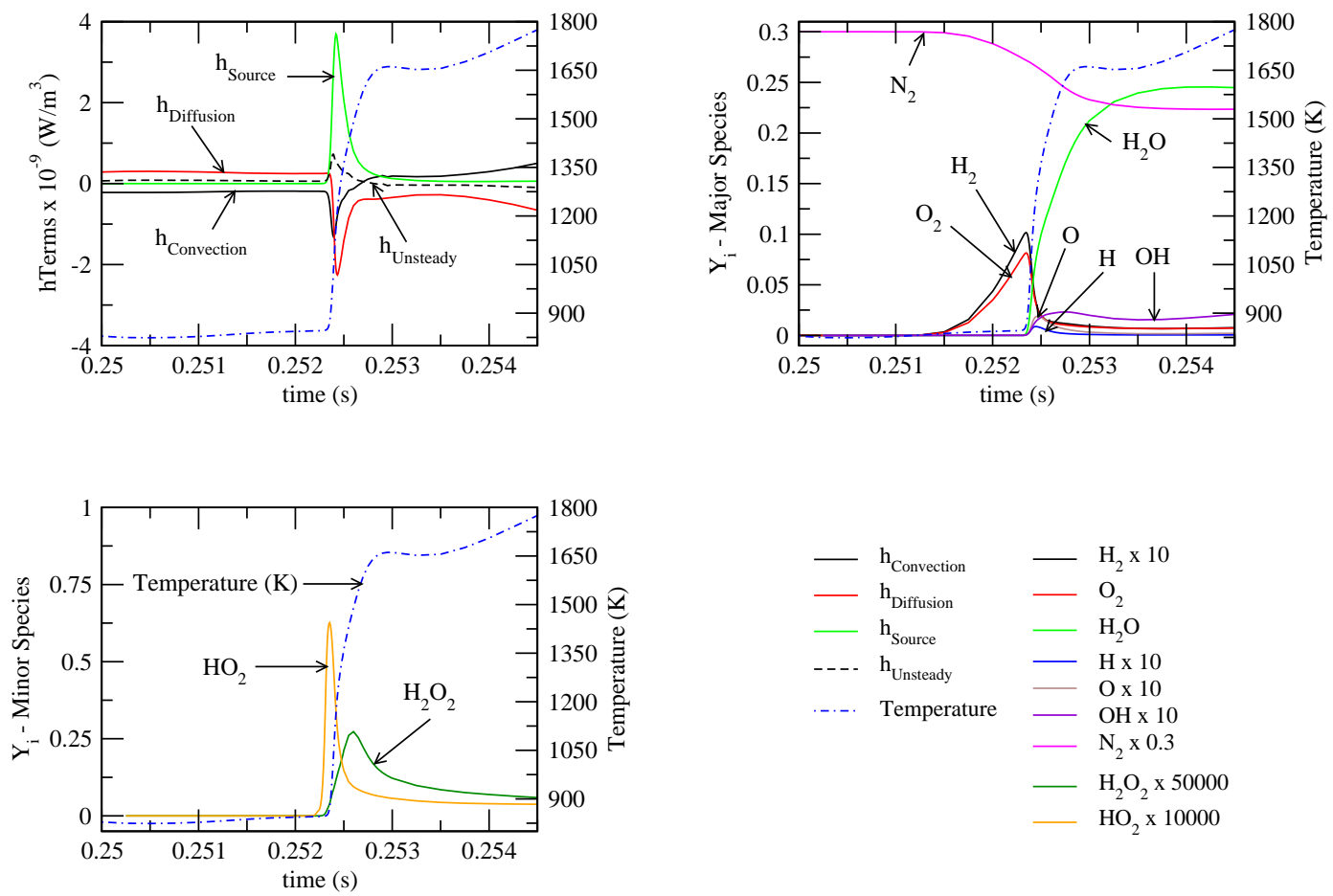

Figure 10: Temporal evolution of each term in the energy equation, temperature and species mass fractions near the ignition location $\left(\theta=0^{\circ}\right)$ for $\mathrm{T}_{\text {sphere }}=1200 \mathrm{~K}$. 

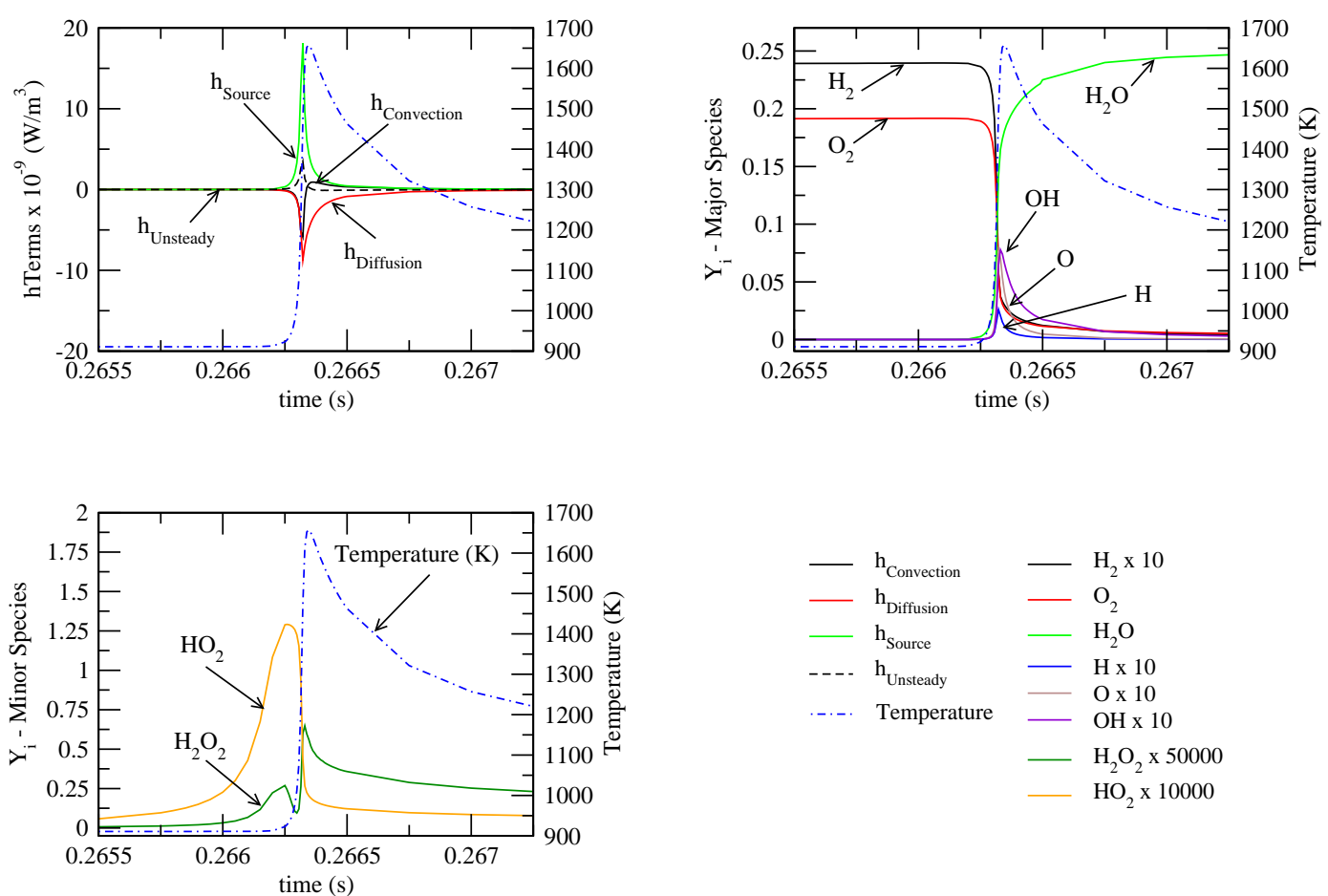

Figure 11: Temporal evolution of each term in the energy equation, temperature and species mass fractions near the ignition location $\left(\theta=115^{\circ}\right)$ for $\mathrm{T}_{\text {sphere }}=960 \mathrm{~K}$.

At $\mathrm{T}_{\text {sphere }}=960 \mathrm{~K}$, the gas temperature between the surface and the flame front drops after ignition indicating heat conduction from hot combustion products to the sphere surface. At $\mathrm{T}_{\text {sphere }}=1200 \mathrm{~K}$ however, the gas temperature near the surface increases to the adiabatic value because the ignition location is further away than for $960 \mathrm{~K}$ which limits heat conduction in the time frame considered. The major species profiles show fresh combustible mixture penetrating the thermal boundary layer, displacing the $\mathrm{N}_{2}$ as shown by the increase of mass fractions of $\mathrm{H}_{2}$ and $\mathrm{O}_{2}$, and decrease of $\mathrm{N}_{2}$ starting at $t=0.2515 \mathrm{~s}$. In the minor species profiles at $960 \mathrm{~K}$ there is a local maximum in the mass fraction of $\mathrm{H}_{2} \mathrm{O}_{2}$ before ignition, this is in contrast with the evolution of this species at $1200 \mathrm{~K}$ where it peaks only after ignition takes place. Before ignition, a significant build-up of $\mathrm{HO}_{2}$ radicals is observed. This feature is more pronounced in the $960 \mathrm{~K}$ case. The evolution described is consistent with previous studies that have demonstrated the importance of peroxide species in low temperature combustion [37]. 
The reaction pathway analysis is summarized in Fig. 12. The main difference between the two ignition cases lies in the formation and consumption pathways of the reactive radicals $\mathrm{H}, \mathrm{O}$ and $\mathrm{OH}$. At high temperatures, $\mathrm{T}_{\text {sphere }}=1200 \mathrm{~K}$, the hydroxyl radical is mostly $(77 \%)$ formed by the two chain branching reactions $R_{1}$ : $\mathrm{H}+\mathrm{O}_{2}=\mathrm{OH}+\mathrm{O}$ and $\mathrm{R}_{2}: \mathrm{O}+\mathrm{H}_{2}=\mathrm{OH}+\mathrm{H}$. The rest is produced by the reaction $\mathrm{R}_{3}: \mathrm{HO}_{2}+\mathrm{H}=\mathrm{OH}+\mathrm{OH}$. The $\mathrm{O}$ atom is formed and consumed via $\mathrm{R}_{1}$ and $\mathrm{R}_{2}$. For the $\mathrm{H}$ atoms $\mathrm{R}_{4}: \mathrm{H}_{2}+\mathrm{OH}=\mathrm{H}_{2} \mathrm{O}+\mathrm{H}$, is the main formation path and $\mathrm{R}_{1}$ the main consumption path. At low temperature, $\mathrm{T}_{\text {sphere }}=960 \mathrm{~K}$, the formation of $\mathrm{OH}$ $(38 \%)$ is due to the following sequence: $\mathrm{R}_{5}: \mathrm{H}+\mathrm{O}_{2}(+\mathrm{M})=\mathrm{HO}_{2}(+\mathrm{M}) ; \mathrm{R}_{3}: \mathrm{HO}_{2}+$ $\mathrm{H}=\mathrm{OH}+\mathrm{OH}$. The chain branching reactions contribute $42 \%$ of the $\mathrm{OH}$ and $\mathrm{R}_{6}$ : $\mathrm{H}+\mathrm{O}(+\mathrm{M})=\mathrm{OH}(+\mathrm{M})$ amounts to $16 \%$. The importance of the chain branching process in the formation and consumption of the $\mathrm{O}$ atom and the consumption of $\mathrm{H}$ atom also decreases at $\mathrm{T}_{\text {sphere }}=960 \mathrm{~K}$ compared to $1200 \mathrm{~K}$. It can be concluded that the ignition close to the threshold is delayed due to the enhanced competition between fast and direct formation of active centers via chain branching reactions and slower and indirect pathways involving linear chain processes. 


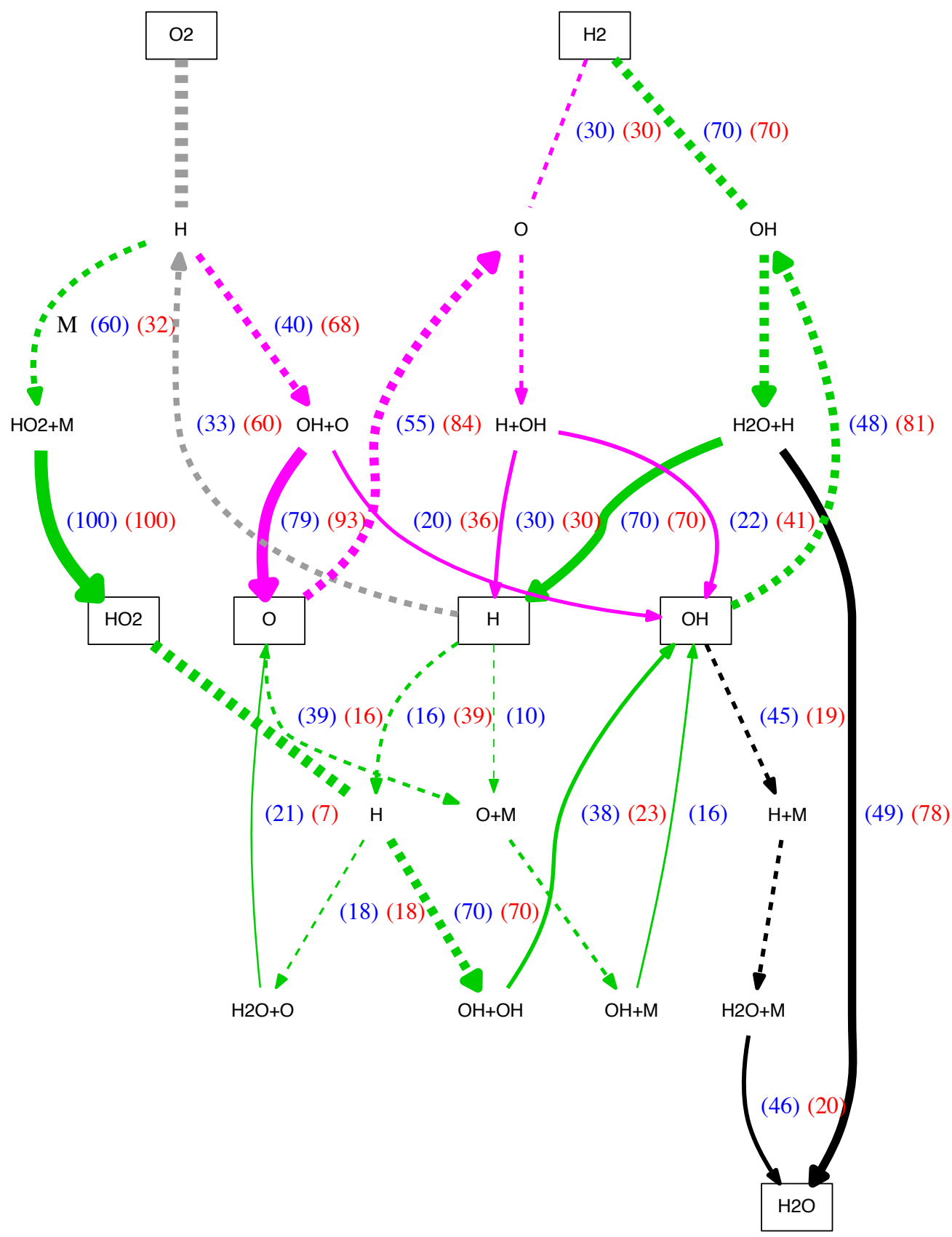

Figure 12: Reaction pathway analysis near the ignition location for $\mathrm{T}_{\text {sphere }}=1200 \mathrm{~K}$ (in red) and $\mathrm{T}_{\text {sphere }}=960 \mathrm{~K}$ (in blue). Boxes represent species reservoirs, solid lines are reservoir inputs, and dashed lines are reservoir outputs. Green: non chain branching pathways; Magenta: chain branching pathways; Grey: mixed pathways 


\section{Conclusion}

Two-dimensional simulations were performed of the transient viscous, reactive flow and ignition of a stoichiometric hydrogen/air mixture by a moving hot sphere, as it penetrates through an interface between an inert $\left(\mathrm{N}_{2}\right)$ and reactive $\left(\mathrm{H}_{2}\right.$-air) mixture. Two distinct ignition behaviors were observed: (1) For temperatures far above the ignition threshold, reaction starts upon contact with the reactive mixture, and ignition occurs between the front stagnation point and separation region depending upon the sphere's surface temperature. Because the ignition time is very short, there is not enough time for the pure $\mathrm{N}_{2}$ in the thermal boundary layer to be flushed out by the fresh reactive mixture and ignition takes place in a more diluted mixture. (2) Closer to the ignition threshold, the induction time is significantly longer, and the reaction rates are not fast enough to release sufficient heat and trigger fuel conversion into products during the transit of the gas from the front stagnation point to the separation region. However separation of the boundary layer results in a zone where reactive mixture is essentially trapped, conduction of heat from the sphere to the gas takes place readily, and convective losses are minimal. The volume of gas in the separation region appears to ignite homogeneously.

The large differences observed between the ignition times obtained from the two-dimensional and adiabatic constant pressure simulations are due in part to the absence of convective and diffusive losses in the constant pressure computations, and more importantly to the presence of an initially inert boundary layer that needs to be flushed out before any chemical activity can occur. These differences, and the increased importance of diffusive processes within the boundary layer as the ignition threshold is approached indicate that simplified models based on comparison of residence times with ignition delay times alone are inappropriate for an accurate prediction of ignition thresholds in flows where ignition takes place within a thermal boundary layer next to a hot surface. Detailed multidimensional simulations are necessary to capture important features in the flow field such as boundary layer separation, and energy transport processes which play a significant role in the ignition process. 


\section{Acknowledgments}

This work was carried out in the Explosion Dynamics Laboratory of the California Institute of Technology. J. Melguizo-Gavilanes was supported by the Natural Sciences and Engineering Research Council of Canada (NSERC) Postdoctoral Fellowship Program. R. Mével, S. Coronel and J.E. Shepherd by The Boeing Company through a Strategic Research and Development Relationship Agreement CT-BAGTA-1. This work used the Extreme Science and Engineering Discovery Environment (XSEDE), which is supported by National Science Foundation grant number ACI-1053575. 


\section{References}

[1] Guidelines for determining the probability of ignition of a released flammable mass, Center for Chemical Process Safety, AIChE 2nd Edition, 2014.

[2] Brabrauskas, V., Ignition Handbook, 2003, Fire Science Publishers.

[3] Service History/Fuel Tank Safety Level Assessment, Federal Aviation Administration (FAA), Technical Report TG1, 1998.

[4] Fisher, F. A., Plumer, J. A. and Perala, R. A., Aircraft Lightning Protection Handbook, Technical Report DOT/FAA/CT-89/22, 1989, Lighting Technologies Inc.

[5] Rupke, E., Lightning Direct Effects Handbook, Technical Report AGATEWP3.1-031027-043, 2002, Lighting Technologies Inc.

[6] Feraboli, P. and Miller, M., Damage resistance and tolerance of carbon/epoxy composite coupons subjected to simulated lightning strike, Composites Part A: Applied Science and Manufacturing, 2009, 40(6-7), pp. 954-967

[7] Silver, R.S., The ignition of gaseous mixtures by hot particles, The London, Edinburgh, and Dublin Philosophical Magazine and Journal of Science, 1937, 23(156), pp. 633-657

[8] Beyer, M. and Markus, D., Ignition of explosive atmospheres by small hot particles : Comparison of experiments and simulations, Science and Technology of Energetic Materials, 2012

[9] Roth, D., Sharma, P., Haeber, T., Schiessl, R., Bockhorn, H., and Maas, U., Ignition by mechanical sparks: ignition of hydrogen/air mixtures by submillimeter-sized hot particles, Combustion Science and Technology, 2014, 186(10-11), pp. 1606-1617

[10] Dubaniewicz, T. H., Cashdollar, K.L., Green, G.M. and Robert F.C., Continuous wave laser ignition thresholds of coal dust clouds, Journal of Laser Applications, 2003, 15(3), pp. 184-191 
[11] Dubaniewicz, T. H., Cashdollar, K.L. and Green, G.M., Continuous wave laser ignition thresholds of coal dust clouds, Journal of Laser Applications, 2003, 15(3), pp. 184-191

[12] Dubaniewicz, T. H., Threshold powers and delays for igniting propane and butane-air mixtures by cw laser-heated small particles, Journal of Laser Applications, 2006, 18(4), pp. 312-319

[13] Beyrau, F., Hadjipanayis, M.A. and Lindstedt, R.P., Ignition of fuel/air mixtures by radiatively heated particles, Proceedings of the Combustion Institute, 2013, 34, pp. 2065-2072

[14] Bothe, H., Schenk, S., Hawksworth, S., Carleton, F.B. and Weinberg, F.J., The safe use of optics in potentially explosive atmospheres, Explosion Safety in Hazardous Areas. International Conference on (Conf. Publ. No. 469), 1999, pp. $44-49$

[15] Homan, H. S., Minimum mass of burning aluminum particles for ignition of methane/air and propane/air mixtures, Proceedings of Eighteenth Symposium (International) on Combustion, 1981, pp. 1709-1717

[16] Paterson, S., I. The ignition of inflammable gases by hot moving particles, The London, Edinburgh, and Dublin Philosophical Magazine and Journal of Science, 1939, 28(186), pp. 1-23

[17] Paterson, S., II. The ignition of inflammable gases by hot moving particles, The London, Edinburgh, and Dublin Philosophical Magazine and Journal of Science, 1940, 30(203), pp. 437-457

[18] C.K. Law, On the stagnation-point ignition of a premixed combustible, International Journal of Heat and Mass Transfer, 1978, 21, pp. 1363-1368

[19] C.K. Law, Ignition of a combustible mixture by a hot particle, The American Institute of Aeronautics and Stronautics Journal, 1978, 16(6), pp. 628-630 
[20] Y.B. Zel'dovich, G.I. Barenblatt, V.B. Librovich, G.M. Makhviladze, The Mathematical Theory of Combustion and Explosions, Consultants Bureau, New York NY, USA, 1985, p.597

[21] A.M. Golovin, The ignition of a combustible mixture by a hot particle, High Temperature, 1996, 34(1), pp. 105-111

[22] Poinsot, T. and Veynante, D., Theoretical and Numerical Combustion, 2005, Edwards.

[23] Smooke, M. D., The computation of laminar flames, Proceedings of the Combustion Institute, 2013, 34, pp. 65-98

[24] Melguizo-Gavilanes, J., Mével, R., Coronel, S. and Shepherd, J.E. Effect of differential diffusion on ignition of stoichiometric hydrogen-air by moving hot spheres, Proceedings of the Combustion Institute, 2015, Accepted for oral presentation. Currently in review for publication.

[25] Weller, H.G., Tabor, G., Jasak, H., and Fureby, C., A tensorial approach to continuum mechanics using object-oriented techniques, Journal of Computational Physics, 1998, 12, pp. 620-631

[26] Saad, Y., Iterative methods for sparse linear systems, 2003, Society for Industrial and Applied Mathematics, Philadelphia.

[27] Demirdzic, I., Lilek, Z. and Péric, M. (1993). A collocated finite volume method for predicting flows at all speeds. International Journal for Numerical Methods in Fluids, 16, pp. 1029-1050.

[28] Oran, E.S. and Boris, J.P., Numerical Simulation of Reactive Flow, 2001, Cambridge University Press.

[29] Mével, R., Javoy, S., Lafosse, F., Chaumeix, N., Dupré, G. and Paillard, C.E., Hydrogen-nitrous oxide delay time: shock tube experimental study and kinetic modelling, Proceedings of The Combustion Institute, 2009, 32, pp. 359-366. 
[30] Mével, R., Javoy, S. and Dupré, G., A chemical kinetic study of the oxidation of silane by nitrous oxide, nitric oxide and oxygen, Proceedings of The Combustion Institute, 2011, 33, pp. 485-492.

[31] Sutherland, W., The viscosity of gases and molecular force, Philosophical Magazine Series 5, 1893, 36, pp. 507-531.

[32] B. Poling, J. Prausnitz, J. O'Connell, The Properties of Gases and Liquids, McGraw Hill Professional, 5th Edition, McGraw-Hill Education, 2000, p.804.

[33] A. Burcat, R. Branko, Third Millenium Ideal Gas and Condensed Phase Thermochemical Database for Combustion (with Update from Active Thermochemical Tables). Argonne National Laboratory (ANL), July 29, 2005.

[34] Coronel, S.A., Menon, S., Mével, R., Blanquart, G. and Shepherd, J. E., Ignition of nitrogen diluted hexane-oxygen mixtures by moving heated particles, Proceedings of the International Colloquium on the Dynamics of Explosions and Reactive Systems, 2013, 24.

[35] Browne, S., Liang, Z. and Shepherd, J.E., Detailed and simplified chemical reaction mechanisms for detonation simulation. Paper 05F-21 - Fall 2005 Western States Section of the Combustion Institute, Stanford University, Oct. 17-18, 2005.

[36] Semenov, N.N., Chain Reactions, 1934, Goskhimizdat, Leningrad. Translation Oxford (1935).

[37] Glassman, I., Combustion, 2008, Academic Press, San Diego, 4th edition Press. 